\title{
MECHANISM OF CHLORAMPHENICOL-RESISTANCE MEDIATED BY kR102 FACTOR IN PSEUDOMONAS AERUGINOSA
}

\author{
Megumi Kono and Koji O'hara \\ Department of Microbiology, Tokyo College of Pharmacy, \\ 1-10-19, Ueno-sakuragi, Taito-ku, Tokyo 110, Japan \\ (Received for publication October 27, 1975)
}

\begin{abstract}
The chloramphenicol (CP)-resistance mechanism of five-drug-resistant $\mathrm{R}$ factor (kR102) of Pseudomonas aeruginosa K-Ps 102 derived from a clinical specimen was investigated. Neither inactivation by acetyltransferase of CP nor induced resistance by $\mathrm{CP}$ was recognized. Reduced affinity of the ribosome to the drug was not seen in the result of incorporation experiment of ${ }^{14} \mathrm{C}$-valine by phage f 2 RNA and ribosome of $\mathrm{K}-\mathrm{Ps}$ 102. However, on spheroplasts by glycine treatment, remarkable increase of CP susceptibility was observed. From the above evidence, it was considered that the CP-resistance barrier controlled by kR102 factor would be in the cell wall and the surface layer of cytoplasma and that the mechanism of CP-resistance was possibly by decreased membrane permeability of $\mathrm{CP}$. However, the susceptibility to $\mathrm{CP}$ of the susceptible strain still increased by the formation of spheroplasts. Consequently, it was considered that $\mathrm{R}$ factor might be controlling the function of membrane permeability of the cells.
\end{abstract}

The mechanism of chloramphenicol $(\mathrm{CP})$ resistance has been shown to be due to $\mathrm{CP}$ inactivation by the $\mathrm{CP}$ acetyltransferase (CATase) in Staphylococci having CP-resistant plasmid ${ }^{13}$ or in enteric bacteria having $\mathrm{R}$ factor ${ }^{2)}$. However, as to some Escherichia coli being resistant owing to $\mathrm{R}$ factor, decrease of membrane permeability of $\mathrm{CP}$ is reported to be the mechanism of increased resistance. ${ }^{3)}$

Recently, $\mathrm{R}$ factor has been found in Pseudomonas aeruginosa, but there is not yet any report on the mechanism of $\mathrm{CP}$-resistance controlled by $\mathrm{R}$ factor of $P$. aeruginosa. This paper deals with the mechanism of CP-resistance controlled by kR102 factor derived from $P$. aeruginosa strain, K-Ps 102.

\section{Materials and Methods}

Strains used: We used P. aeruginosa strains, K-Ps 102, having R factor (kR102) resistant to five drugs; tetracycline (TC), CP, streptomycin (SM), sulfonamide (SA), and kanamycin (KM); rifampicin (RFP) resistant mutant (K-Ps 47 RFP) of sensitive $P$. aeruginosa strain K-Ps 47 , and the conjugant strain K-Ps 47 RFP (kR102) obtained from K-Ps 47 RFP by mating with K-Ps 102.4) E. coli K-12 W3110 RFP (R100-1), which was an RFP resistant mutant of $E$. coli W3110 having R100-1 factor ${ }^{2)}$ (resistant to TC, CP, SM and SA), was employed as a reference strain for CP-inactivation.

Media: These studies were conducted using brain heart infusion broth (Difco: BHI) containing $0.4 \% \mathrm{KNO}_{3}(\mathrm{~K}-\mathrm{BHI})$ for the CP-pretreatment experiment, medium $\mathrm{B}$ (nutrient broth: Eiken) for preparation of the crude enzyme, and tryptone medium ( $10 \mathrm{~g}$ of Polypeptone, $8 \mathrm{~g}$ of $\mathrm{NaCl}, 1 \mathrm{~g}$ of yeast extract powder, $1 \mathrm{~g}$ of glucose and $2 \mathrm{ml}$ of $1 \mathrm{M} \mathrm{CaCl}_{2}$ in 1 liter; $\mathrm{pH} \mathrm{7.2)}$ for preparation of ribosomes and for multiplication of phage f2. For spheroplast formation, medium BS (medium B containing $12 \%$ saccharose) and medium BGS (medium BS containing $3 \%$ glycine) were used. Agar was added to them, if necessary, to use them as a solid medium. 
Determination of minimum inhibitory concentration (MIC): An overnight culture of bacteria in peptone water was diluted 100 times, and a platinum loop of the dilution was inoculated to nutrient agar plates containing various concentrations of each drug. After culturing overnight at $37^{\circ} \mathrm{C}$, the MIC was determined. MIC on $\mathrm{CP}$-pretreatment was determined similarly on the bacteria cultured overnight with peptone water containing various concentrations of $\mathrm{CP}$ lower than MIC.

Determination of $50 \%$ growth inhibition dose $\left(\mathrm{ID}_{50}\right)$ : Each $0.1 \mathrm{ml}$ of bacterial culture in the exponential growth phase was added to $10 \mathrm{ml}$ of $\mathrm{K}$-BHI containing various concentrations of $\mathrm{CP}$, and the growth curve was recorded for 6 hours by Jouan-Biophotometer (Paris). From the growth $\%$ in the exponential phase, $\mathrm{ID}_{50}$ was obtained according to TrefFer's method. ${ }^{5)}$ $\mathrm{ID}_{50}$ on CP-pretreatment was similarly determined on the bacteria cultured for 2 hours in K-BHI containing various concentrations of $\mathrm{CP}$ less than MIC.

Determination of CP-inactivation: The reaction was carried out according to the system of enzymatic inactivation of aminoglycoside antibiotics reported previously, ${ }^{\text {b) }}$ except that it was performed at $37^{\circ} \mathrm{C}$ for 18 hours and the residual potency of the antibiotic after the reaction was determined with Sarcina lutea ATCC 9341.

Determination of chloramphenicol acetyltransferase (CATase) activity: The activity was determined according to the method reported previously, ${ }^{2)}$ as using acetyl $\mathrm{CoA}$ and dithiobisnitrobenzoic acid (DTN). Protein content was determined according to the method of LowRY et al. ${ }^{\text {r) }}$

Formation of spheroplasts: To $1 \mathrm{ml}$ of the overnight culture in medium B, $9 \mathrm{ml}$ of fresh medium B was added, and cultured to obtain $0.5 \mathrm{OD}$ at $600 \mathrm{~nm}$; to $1 \mathrm{ml}$ of the culture $9 \mathrm{ml}$ of medium BGS was added and subjected to shaking culture for 3 hours. After confirming formation of spheroplasts, the culture was diluted adequately with medium BS or sterilized water, spread onto medium BS-agar and medium B-agar, and incubated overnight at $37^{\circ} \mathrm{C}$. The number of bacteria was counted and the number of spheroplasts was obtained by subtracting the number of colonies on the medium B agar (colonies of which were not converted to spheroplasts) from the number of colonies on the medium BS-agar (total colonies) ${ }^{8)}$

Determination of incorporation of ${ }^{14} \mathrm{C}$-valine: S-105 fraction and ribosomes were prepared according to the method of Modollel and DAvis, ${ }^{92}$ and phage f 2 RNA was prepared according to the method of GestLAND. ${ }^{10)}$ The reaction was carried out according to the method of TsenG et al. ${ }^{11)}$ with the following reaction mixture: $60 \mathrm{~mm}$ Tris buffer, $\mathrm{pH} 7.8 ; 30 \mathrm{~mm} \mathrm{NH}_{4} \mathrm{Cl} ; 10$ $\mathrm{mm}$ Mg-acetate; $10 \mathrm{~mm}$ reduced glutathione; $1 \mathrm{~mm}$ adenosine triphosphate (ATP); $0.2 \mathrm{~mm}$ guanosine triphosphate (GTP); $5 \mathrm{~mm}$ creatine phosphate; $50 \mathrm{mcg}$ creatine kinase $(\mathrm{Sigma}) / \mathrm{ml}$; $0.05 \mathrm{~mm}$ amino acids of 19 kinds other than valine; $0.03 \mathrm{~mm}{ }^{14} \mathrm{C}$-valine $(225 \mathrm{mCi} / \mathrm{mmole}$, Daiichi Kagaku); $0.1 \mathrm{mg}$ phage f2 RNA/ml; $1 \mathrm{mg}$ E. coli W, t-RNA/ml (Sigma); 0.2 volume of S-105 fraction and 0.2 volume of ribosome suspension $(10 \mathrm{mg} / \mathrm{ml})$; and adequate amount of CP.

All the above materials except f2-RNA and ${ }^{14} \mathrm{C}$-valine were mixed, and after allowing to stand at $34^{\circ} \mathrm{C}$ for 10 minutes, the additional two materials were added to react at the same temperature for 30 minutes. Fifty $\mu \mathrm{l}$ of the reaction mixture was removed, and after adding $0.5 \mathrm{ml}$ of cold $5 \%$ trichloroacetic acid (TCA), the mixture was heated at $90^{\circ} \mathrm{C}$ for 15 minutes, filtered through membrane filter (Toyo Roshi Ltd; TM-2, $0.45 \mu$; size, $13 \mathrm{~m} / \mathrm{m}$ ), and rinsed four times repeatedly with $1 \mathrm{ml}$ of $5 \%$ TCA. ${ }^{14} \mathrm{C}$-Valine on the filter was determined by a liquid scintillation counter of Packard 3330 Type. The solvent for the liquid scintillation was prepared with a base of toluene ( $5 \mathrm{~g}$ of 2, 5-diphenyloxazol (POP), $0.3 \mathrm{~g}$ of dimethyl-POPOP, and 1 liter of toluene).

\section{Results}

CP Sensitivity and its Induced-Resistance by the Drug

MIC values of $P$. aeruginosa strains revealed that CP susceptibility was not different between the donor strain having $\mathrm{R}$ factor and the conjugant strain which accepted the $\mathrm{R}$ factor. 
Increase of the resistance by CP pretreatment was not observed by determining MIC and in the comparison of $\mathrm{ID}_{50}$ value which is considered to be the most sensitive to the change of the susceptibility for antibiotics. Table 1 shows the results when using the concentrations of $25 \mathrm{mcg} / \mathrm{ml}$ with a CP-resistant strain and of $6.25 \mathrm{mcg} / \mathrm{ml}$ with a CP-susceptible strain on $\mathrm{CP}$ pretreatment. Though the data are not shown here, induction of CP-resistance on pretreatment with $25 \mathrm{mcg}$ of $\mathrm{CP} / \mathrm{ml}$ was not recognized with the other five strains of $P$. aeruginosa having $\mathrm{CP}$-resistant $\mathrm{R}$ factors reported previously.4)

\section{Mechanism of CP-resistance Controlled} by $\mathrm{R}$ Factor, kR102

The test strains were ruptured by means of supersonic oscillation, and the supernatant $(30,000 \times g)$ thus obtained was used to examine $\mathrm{CP}$ inactivation in the presence of ATP, CoA, and $\mathrm{Mg}$-acetate, or in the presence of acetylCOA and DTN. The results are shown in Table 2. As can be seen in the table, only the reference strain of E. coli W3110 RFP (R100-1) having CATase activity showed CPinactivation in every determination, but three other $P$. aeruginosa strains could not inactivate CP. CP inactivation with intact cells of the above strains in the presence of $50 \mathrm{mcg} / \mathrm{ml}$

Table 1. Comparison of chloramphenicol(CP) resistance of $P$. aeruginosa pretreated with or without $\mathrm{CP}$

\begin{tabular}{l|r|c|c|c}
\hline \multirow{2}{*}{ Strain } & \multicolumn{2}{|c|}{ MIC } & \multicolumn{2}{|c}{ ID $_{50}$} \\
\cline { 2 - 5 } & - & + & - & $+*$ \\
\hline K-Ps 102 & 1,600 & 1,600 & 50 & 60 \\
K-Ps 47 RFP & 100 & $50 * *$ & 4.2 & $3.1 * *$ \\
K-Ps 47 RFP & 1,600 & 1,600 & 56 & 49 \\
(kR 102) & & & & \\
\hline$* \quad$ Pretreatment with $25 \mathrm{mcg}$ of $\mathrm{CP} / \mathrm{ml}$, yes $(+)$, \\
not(-) \\
$* * \quad$ Pretreatment with $1.6 \mathrm{mcg}$ of $\mathrm{CP} / \mathrm{ml}$
\end{tabular}

Table 2. Inactivation of chloramphenicol(CP) and the $\mathrm{CP}$-acetyltransferase (CATase) activity by crude extracts from various strains

\begin{tabular}{l|c|c}
\hline Crude extract from & Inactivation & $\begin{array}{c}\text { Specific } \\
\text { enzyme } \\
\text { activity* } \\
\text { (units/mg } \\
\text { of protein) }\end{array}$ \\
\hline K-Ps 102 & - & $<0.0005$ \\
K-Ps 47 RFP & - & $<0.0005$ \\
K-Ps 47 RFP (kR102) & - & $<0.0005$ \\
\hline W3110 RFP (R100-1) & + & 1.30 \\
\hline$* \quad$ Acetylation of 1 $1 \mu$ mole of CP/min/mg of \\
protein
\end{tabular}

Fig. 1. Chloramphenicol(CP) and tetracycline(TC) resistance of either intact cells or spheroplast of $P$. aeruginosa strains

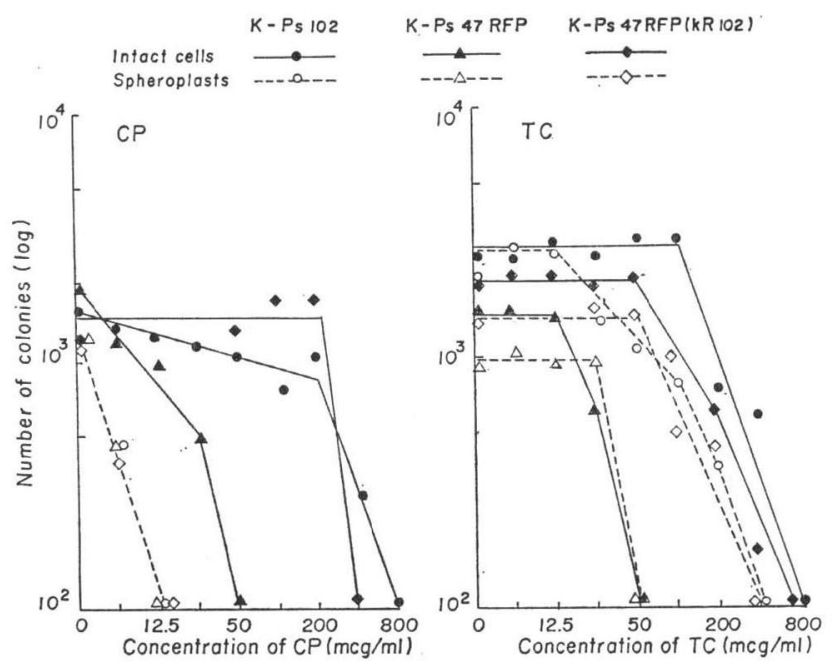


of CP was also not recognized

Then, the CP susceptibility of spheroplasts of the strain by glycine treatment was examined and simultaneously TC susceptibility was observed ${ }^{12)}$ (Fig. 1). The TC susceptibility of K-Ps 102 and K-Ps 47 RFP (kR102) increased up to $400 \mathrm{mcg} / \mathrm{ml}$, while CP susceptibility was observed to increase greatly; it increased up to $12.5 \mathrm{mcg} / \mathrm{ml}$ in K-Ps $47 \mathrm{RFP}$, and each strain was also sensitized up to the same level.

Ribosomes were extracted from each strain and the CP susceptibility was observed and the results were shown in Table 3 . There had been no report on determination of the CP suscepti-

Table 3. Inhibition of amino acid incorporation by chloramphenicol in cell-free systems obtained from $P$. aeruginosa strains

\begin{tabular}{l|c|c}
\hline \multicolumn{1}{c|}{ Strain* } & $\begin{array}{c}\text { Concentra- } \\
\text { tion of } \\
\text { CP (mcg/ml) }\end{array}$ & $\begin{array}{c}\text { Incorpora- } \\
\text { tion of }{ }^{14} \mathrm{C}- \\
\text { valine } \\
\text { (cpm)** }\end{array}$ \\
\hline K-Ps 102 & 0 & 1134 \\
& 20 & 147 \\
50 & 0 \\
\hline K-Ps 47 RFP & 0 & 933 \\
& 20 & 168 \\
& 50 & 5 \\
\hline K-Ps 47 RFP (kR102) & 0 & 907 \\
& 20 & 226 \\
& 50 & 9 \\
\hline
\end{tabular}

* The strains were used as a source of the ribosomes or S-105 fractions which were prepared as described in Materials and Methods.

** Background counts per minute were 105 on an average. transfer to $E$. coli has not been recognized. Ribosomes of K-Ps 102 are known to exhibit SMresistance (unpublished data). And it has been reported that most of $P$. aeruginosa strains showed low levels of CATase activity, which, however, did not appear sufficient to explain their resistance. ${ }^{13)}$ We also tried to detect CATase as to the strains used, according to the method of Окамото et al. using $\mathrm{CH}_{3}{ }^{14} \mathrm{COONa}$, ATP, CoA, each crude extract and CP. From the results, 3-O-monoacetyl CP and 1,3-O-diacetyl CP were found only in the reference strain (E. coli W3110 RFP (R100-1)). However, these inactivated products were not observed in K-Ps 102, K-Ps 47 RFP and K-Ps 47 RFP (kR102) (unpublished data).

Therefore, as described in this report, it is revealed that CP-resistance by kR 102 factor is not due to inactivation by acetylation nor due to resistance of ribosome, but the mechanism of resistance development is decrease of permeability of CP into cells. A similar $\mathrm{R}$ factor having such a special resistance mechanism is R70 factor of $E$. coli reported by NaGAI and MitsuHASHI. ${ }^{3)}$ R70 factor was reported to show induction of resistance by $C P$, but it is quite different in $\mathrm{kR} 102$, as induction of CP-resistance was not seen in the latter. Increase of sensitivity to CP of spheroplasts was specific to CP, and it seemed to be a factor as barrier of sensitivity between cell wall and cell membrane, since it was greatly changed by injury of the cell wall. In both of the donor of $\mathrm{R}$ factor and the resistant strain receiving $\mathrm{R}$ factor, the behaviors of the sensitivities of the intact cells and the spheroplasts were quite the same, and also the sensitive strain K-Ps 47 RFP increased its sensitivity in spheroplasts up to the same degree to that of $\mathrm{R}^{+}$strain: 
it suggest the existence of ultra-sensitive strain having the sensitivity higher than that of K-Ps $47 \mathrm{RFP}$. Such an ultra-sensitive strain (MIC: less than $25 \mathrm{mcg} / \mathrm{ml} \mathrm{of} \mathrm{CP)} \mathrm{was} \mathrm{found} \mathrm{in} 2 \%$ of the strains examined. However, the growth of these strains was slightly observed on overnight cultivation in the broth containing $25 \mathrm{mcg}$ of $\mathrm{CP} / \mathrm{ml}$, and the MIC of the culture became the same to that of K-Ps 47 RFP. The phenomenon has not been further discussed. The difference of the sensitivity between the spheroplasts and the intact cells of K-Ps 47 RFP should suggest the existence of barrier in the cell wall, which is thought as a resistance mechanism of kR102 factor. Accordingly, the resistance mechanism of $\mathrm{R}$ factor might be qualitative or quantitative control of the barrier, which is easily separated from the cell surface on the formation of spheroplasts. $\mathrm{R}$ factor whose resistance mechanism is not inactivation should be noticed as well as R70 factor reported by Nagai and Mitsuhashi. ${ }^{3)}$

\section{References}

1) Kono, M.; K. Ogawa \& S. Mitsuhashi: Drug resistance of staphylococci. VI. Genetic determinant for chloramphenicol resistance. J. Bact. 95: 886 892, 1968

2) Iyobe, S.; M. Kono, K. O'hara, H. Hashimoto \& S. Mrtsuhashi: Relationship between chloramphenicol acetyltransferase activity and the number of resistance genes. Antimicr. Agents \& Chemoth. 5: $68 \sim 74,1974$

3) Nagai, Y. \& S. Mitsuhashi: New type of R factors incapable of inactivating chloramphenicol. J. Bact. 109: 1 7, 1972

4) Kono, M. \& K. O'hara: Prevalence of R factors in Pseudomonas aeruginosa. J. Gen. Microbiol. 91: $191 \sim 194,1975$

5) Treffers, H. P.: The linear representation of dosage-response curves in microbial-antibiotic assays. J. Bact. 72: 108 114, 1956

6) O'hara, K.; M. Kono \& S. Mitsuhashi: Enzymatic inactivation of a new aminoglycoside antibiotic, sisomicin, by resistant strains of Pseudomonas aeruginosa. Antimicr. Agents \& Chemoth. 5: $558 \sim 561,1974$

7) Lowry, O. H.; N. J. Rosebrough, A. L. Farr \& R. J. Randall: Protein measurement with Folin phenol reagent. J. Biol. Chem. 193: 265 275, 1951

8) Kawakami, M.; N. Osawa \& S. Mitsuhashi: Transmission of the drug resistance factor between spheroplasts. Jap. J. Exp. Med. 31: 259 266, 1961

9) Modollel, J. \& B. D. Davis: Rapid inhibition of poly peptide chain extension by streptomycin. Proc. Nat. Acad. Sci. 61: 1279 1286, 1968

10) Gestland, R. F.: Some physical properties of bacteriophage R17 and its RNA. J. Mol. Biol. 8: 496 507, 1964

11) Tseng, J. T.; L. E. Bryan \& H. M. Van Den Elzen: Mechanisms and spectrum of streptomycin resistance in a natural population of Pseudomonas aeruginosa. Antimicr. Agents \& Chemoth. 2: $136 \sim 141,1972$

12) O'hara, K. \& M. Kono: Mechanism of tetracycline resistance in Pseudomonas aeruginosa carrying an R factor. J. Antibiotics 28: 607 608, 1975

13) Окамото, S.; Y. Suzuki, K. Mise \& R. NAKaya: Occurrence of chloramphenicol-acetylating enzymes in various gram-negative bacilli. J. Bact. 94: 1616 1622, 1967 